\title{
Fatigue in low-grade glioma
}

\author{
Karin Struik · Martin Klein · Jan J. Heimans • \\ Marieke F. Gielissen · Gijs Bleijenberg · Martin J. Taphoorn • \\ Jaap C. Reijneveld · Tjeerd J. Postma
}

Received: 25 February 2008/Accepted: 4 November 2008/Published online: 9 December 2008

(C) The Author(s) 2008. This article is published with open access at Springerlink.com

\begin{abstract}
The aim of this study was to determine the prevalence and severity of fatigue in long-term survivors with a low-grade glioma (LGG), and to analyze the relationship between fatigue and demographic variables, disease duration, tumor characteristics, former tumor treatment modalities, antiepileptic drug (AED) use, selfreported concentration, motivation, and activity. Fifty-four patients with stable disease (age range, 25-73 years) who were diagnosed and treated more than 8 years ago were included in this study. Fatigue was analyzed with the Checklist Individual Strength (CIS). Thirty-nine percent of the LGG patients were severely fatigued, with older patients being most affected. Severe fatigue was associated with AED use, and with reduced self-reported concentration, motivation, and activity. No relation was found between fatigue and gender, histology, tumor laterality, disease duration, type of neurosurgical intervention and radiation treatment. Fatigue is a severe problem in a large proportion of long-term surviving LGG patients.
\end{abstract}

K. Struik · J. J. Heimans · J. C. Reijneveld · T. J. Postma ( $\square)$ Department of Neurology, VU University Medical Center, P.O. Box 7057, 1007 MB Amsterdam, The Netherlands e-mail: TJ.Postma@vumc.nl

\section{Klein}

Department of Medical Psychology, VU University Medical Center, Amsterdam, The Netherlands

M. F. Gielissen · G. Bleijenberg

Expert Center Chronic Fatigue, Radboud University, Nijmegen Medical Center, Nijmegen, The Netherlands

M. J. Taphoorn

Department of Neurology, Medical Center Haaglanden, Den Haag, The Netherlands
Keywords Fatigue $\cdot$ Low-grade glioma Prevalence studies · Quality of life

\section{Introduction}

Low-grade gliomas are primary malignant brain tumors of glial origin [1]. The median survival time for patients with LGG ranges from 5 to 15 years [2,3], and some patients may survive in a stable state for many years after the diagnosis and initial treatment. Frequent symptoms experienced by patients with LGG are epileptic seizures and cognitive disturbances $[4,5]$.

Fatigue is frequently reported by patients with cancer [6]. During treatment, in advanced stages of the disease, and after curative treatment, fatigue has been described as a major problem. In the last 10 years, the amount of research on the relationship between cancer and fatigue has increased remarkably [7]. However, little is known about the variables associated with the initiation and persistence of cancer-related fatigue [8]. The assumption is that fatigue develops during the treatment phase, but later on there seems to be no clear relationship between persistent fatigue and initial disease and treatment variables [7-11]. Estimations of fatigue during treatment of cancer range from $25 \%$ to $75 \%$ [7]. In addition, based on several cross-sectional and longitudinal studies, fatigue seems to be a problem for a considerable number of cancer survivors [ 7 , 8, 11-14].

Clinical practice suggests that fatigue is also important in glioma patients. However, the level of fatigue and its associated factors have not been studied extensively in LGG patients. Studies assessing fatigue in this patient group mostly use only a limited number of items from a quality of life instrument [15-17]. However, the most 
comprehensive approach to assess fatigue would be using a multidimensional instrument [18], because fatigue is a multidimensional concept with several modes of expression (physical, cognitive, and affective) [7]. In one crosssectional study, fatigue was assessed in 39 LGG patients with help of the European Organization for Research and Treatment of Cancer (EORTC) Core Quality of Life Questionnaire, containing three items for fatigue. The majority of these patients reported tiredness and about half of them had sleep disturbances [15]. In another quality of life study, LGG patients scored higher on the subscale fatigue compared to control subjects, using the Profile of Mood States to measure affective disturbances [16].

In this study the following research questions are addressed: (1) What is the prevalence and severity of fatigue in LGG patients? (2) Is fatigue associated with demographic variables (age and gender), disease duration, tumor characteristics (histology and tumor laterality), former tumor treatment modalities (type of neurosurgical intervention, post-surgery radiotherapy), the use of AEDs, or with self-reported concentration, reduced motivation and activity?

\section{Methods}

\section{Patients}

Fifty-eight patients aged 25-73 (mean 48) years with a LGG diagnosed and treated 8-29 years ago were approached for this study. These patients were part of a group of LGG patients recruited between 1997 and 2000 for a large nationwide study into the neuropsychological status and quality of life [5]. We exclusively approached long-term survivors of a histologically proven LGG without signs of tumor recurrence, and who already participated in a followup study on cognition and quality of life between 2004 and 2005.

\section{Recruitment procedure}

We sent a fatigue questionnaire to the 58 patients, together with a letter from the research coordinator in the summer of 2006, explaining the intention of the study. Furthermore, an informed consent form was enclosed. Those patients who were willing to participate in the study were asked to complete the questionnaire, and sign the informed consent form at home.

\section{Measures}

Fatigue and fatigue related symptoms were measured with the Checklist Individual Strength (CIS). The CIS is a multidimensional fatigue scale; it measures four aspects of fatigue during the previous 2 weeks, namely: fatigue severity (eight items), concentration problems (five items), reduced motivation (four items), and reduced activity (three items) [19, 20]. Each item is scored on a seven-point Likert scale. Total scores of every subscale are obtained by adding the individual items, with high scores indicating a high level of fatigue, a high level of concentration problems, low motivation, and a low level of activity. Patients with a score of 35 or higher on the fatigue severity subscale are considered to be severely fatigued. This cut-off value is based on data obtained in patients with chronic fatigue syndrome [20].

\section{Statistical analysis}

Data analysis was accomplished using SPSS software, version 12.0. As a result of small sample size we had to use a non-parametric approach when selecting statistical methods. Mann-Whitney tests were conducted to test the differences between groups. To test the relation between fatigue and age, disease duration, self-reported concentration, motivation and activity, comparisons were made between severely fatigued (CIS $\geq 35$ ) and non-severely fatigued (CIS < 35) LGG patients. The level of statistical significance for all tests was set at $P$ value less than 0.05 .

\section{Results}

\section{Patient characteristics}

Fifty-four of the 58 patients we approached (93\%) completed and returned the CIS questionnaire. One patient was unable to participate due to foreign residence. One patient declined participation in the study, and the reasons of two other non-participants are unknown. Non-participants did not differ from the participants with respect to gender, histology, disease duration, type of neurosurgical intervention, and AED use. On the other hand, the nonparticipants were slightly younger (mean 43.5 years), and none of them had received radiotherapy. Information about the characteristics of the LGG patients is listed in Table 1.

Fatigue prevalence and severity

The mean CIS-fatigue severity score of the sample LGG patients was 28.2 (SD 15.5). The CIS-fatigue cut-off score of $\geq 35$ for severe fatigue was crossed by 21 patients. Hence, $39 \%$ of the LGG patients experienced severe fatigue. The remaining 33 patients were classified as nonseverely fatigued. 
Table 1 Low-grade glioma patient group $(n=54)$ : characteristics

\begin{tabular}{|c|c|}
\hline Characteristics & Data \\
\hline Mean age ${ }^{a}$ & 48 (SD 11.8, range $25-73)$ \\
\hline Gender: M & $28(52 \%)$ \\
\hline Mean level of education ${ }^{\mathrm{b}}$ & $4.1(\mathrm{SD} 2.0$, range $1-8)$ \\
\hline Mean disease duration ${ }^{\mathrm{a}}$ & $15.0(\mathrm{SD} 4.0$, range $8-29)$ \\
\hline \multicolumn{2}{|l|}{ Histological diagnosis } \\
\hline Astrocytoma & $39(72 \%)$ \\
\hline Oligodendroglioma & $10(19 \%)$ \\
\hline Oligoastrocytoma & $5(9 \%)$ \\
\hline \multicolumn{2}{|l|}{ Tumor location } \\
\hline Left-sided & $32(59 \%)$ \\
\hline Right-sided & $20(37 \%)$ \\
\hline Midline & $2(4 \%)$ \\
\hline \multicolumn{2}{|l|}{ Neurosurgical intervention } \\
\hline Biopsy & $17(31 \%)$ \\
\hline Resection & $37(69 \%)$ \\
\hline \multicolumn{2}{|l|}{ Radiotherapy } \\
\hline Yes & $29(54 \%)$ \\
\hline No & $25(46 \%)$ \\
\hline \multicolumn{2}{|l|}{ Antiepileptic drug use } \\
\hline Yes & $26(48 \%)$ \\
\hline No & $26(48 \%)$ \\
\hline Missing & $2(4 \%)$ \\
\hline \multicolumn{2}{|c|}{ Type of antiepileptic drug use } \\
\hline Monotherapy & $14(54 \%)$ \\
\hline Polytherapy & $12(46 \%)$ \\
\hline
\end{tabular}

Data are number (\%) of patients, unless otherwise indicated

a Years

${ }^{\mathrm{b}}$ Education was assessed by a Dutch scoring system ranging from unfinished primary education (level 1) to university education (level 8)

Fatigue related to patient, tumor and treatment characteristics

To test the relationship between age, disease duration, and fatigue, comparisons were made between severely fatigued (CIS $\geq 35, n=21$ ) and non-severely fatigued (CIS $<35$, $n=33$ ) LGG patients. Severely fatigued patients were older than the non-severely fatigued patients (MannWhitney, $P=0.012$ ). We did not find any differences in disease duration for severely and non-severely fatigued patients (Mann-Whitney, $P=0.404$ ). Fatigue severity was not related to gender (Mann-Whitney, $P=0.640$ ), and no association could be established between histological diagnosis (astrocytoma and oligodendroglioma) and fatigue severity (Mann-Whitney, $P=0.766$ ). Due to the small number of patients with mixed glioma (oligoastrocytoma), data of these patients were excluded from the analyses. Furthermore, the association between tumor laterality and fatigue severity was investigated, while excluding midline tumor locations because of the small sample size $(n=2)$. Results of a Mann-Whitney test indicated that there was no association between tumor laterality and fatigue severity $(P=0.435)$.

No association was found between type of neurosurgical intervention and fatigue severity (Mann-Whitney, $P=0.081$ ). Approximately half of the LGG patients $(n=29)$ received radiotherapy. Again, no effect was found between former radiation treatment and fatigue severity (Mann-Whitney, $P=0.993$ ). However, patients treated with AEDs were more fatigued (Mann-Whitney, $P=0.004)$, irrespective of the use of mono- or polytherapy (Mann-Whitney, $P=0.738$ ) (Table 2).

Fatigue related problems: concentration, motivation and activity

To test the association between fatigue and self-reported concentration, motivation and activity, comparisons were made between severely fatigued (CIS $\geq 35$ ) and nonseverely fatigued (CIS $<35$ ) LGG patients. Severely fatigued LGG patients reported reduced motivation, a lower

Table 2 Tumor and treatment characteristics in relation to fatigue

\begin{tabular}{|c|c|c|c|}
\hline Variables & $\mathrm{N}$ & Mean CIS-fatigue (SD) & $P$-value ${ }^{\mathrm{a}}$ \\
\hline \multicolumn{4}{|l|}{ Histological diagnosis } \\
\hline Astrocytoma & 39 & $27.2(15.2)$ & \multirow[t]{3}{*}{0.766} \\
\hline Oligodendroglioma & 10 & $29.1(18.5)$ & \\
\hline Oligoastrocytoma $^{\mathrm{b}}$ & 5 & $34.6(12.3)$ & \\
\hline \multicolumn{4}{|l|}{ Tumor location } \\
\hline Left-sided & 32 & $27.4(15.5)$ & \multirow[t]{3}{*}{0.435} \\
\hline Right-sided & 20 & $30.7(15.8)$ & \\
\hline Midline $^{\mathrm{b}}$ & 2 & $17.5(13.4)$ & \\
\hline \multicolumn{4}{|c|}{ Neurosurgical intervention } \\
\hline Biopsy & 17 & $33.8(15.7)$ & \multirow[t]{2}{*}{0.081} \\
\hline Resection & 37 & $25.7(15.0)$ & \\
\hline \multicolumn{4}{|l|}{ Radiotherapy } \\
\hline Yes & 29 & $28.3(15.0)$ & \multirow[t]{2}{*}{0.993} \\
\hline No & 25 & $28.2(16.4)$ & \\
\hline \multicolumn{4}{|l|}{ Antiepileptic drug use } \\
\hline Yes & 26 & $34.5(14.6)$ & \multirow[t]{3}{*}{0.004} \\
\hline No & 26 & $22.2(13.9)$ & \\
\hline Missing & 2 & & \\
\hline \multicolumn{4}{|c|}{ Type of antiepileptic drug } \\
\hline Monotherapy & 14 & $33.6(14.6)$ & \multirow[t]{2}{*}{0.738} \\
\hline Polytherapy & 12 & $35.7(15.2)$ & \\
\hline
\end{tabular}

Abbreviation: CIS, Checklist Individual Strength

${ }^{a}$ Mann-Whitney tests were conducted to analyze the association between fatigue and tumor and treatment characteristics

b Variables which were excluded in testing 
Table 3 Fatigue-related problems: concentration, motivation and activity

\begin{tabular}{|c|c|c|c|}
\hline CIS-subscales & $\begin{array}{l}\text { Non-severely } \\
\text { fatigued } \\
\text { patients } \\
(n=33)\end{array}$ & $\begin{array}{l}\text { Severely } \\
\text { fatigued } \\
\text { patients } \\
(n=21)\end{array}$ & $P$-value \\
\hline Mean CIS-concentration (SD) & $14.5(7.8)$ & $26.1(7.5)$ & $<0.001$ \\
\hline Mean CIS-motivation (SD) & $9.5(4.8)$ & $17.0(6.8)$ & $<0.001$ \\
\hline Mean CIS-activity (SD) & $6.4(3.9)$ & $14.5(5.8)$ & $<0.001$ \\
\hline
\end{tabular}

Abbreviation: CIS, Checklist Individual Strength

a The Mann-Whitney test was conducted to test the differences between non-severely and severely fatigued LGG patients

level of activity, and more problems with concentration (Mann-Whitney, $P<0.001$ ) (Table 3).

\section{Discussion}

In this study, we found that $39 \%$ of long-term survivors with a LGG experience severe fatigue. Few studies assessed fatigue in LGG patients [15-17]. In one quality of life study, fatigue is mentioned as a problem for the majority of glioma patients [15]. The current study confirms these results. However, the $39 \%$ prevalence rate of severe fatigue is the highest found among all cancer patients measured with the CIS. Only the percentage of severe fatigue in a sample of breast cancer survivors (38\%) 2.5 years after curative treatment equals our findings [12]. This percentage declines to $24 \%$ after a follow-up period of 2 years. Other cross-sectional and longitudinal studies investigating the prevalence and course of fatigue show similar results, revealing that fatigue continues to decrease during the first years after curative treatment. For about a quarter of cancer survivors fatigue remains a problem [21]. Since the LGG patients in our study finished their treatment more than 8 years ago, the percentage of severe fatigue of nearly $40 \%$ is remarkably high. It is important to note that the LGG population differs from non-glioma cancer populations. In these non-glioma cancer studies, patients are considered to be disease-free. In contrast, LGG patients are considered to be never completely free of disease [5]. As a consequence, being confronted with a life-threatening illness can lead to feelings of depression and anxiety for the future, which both may be correlated with fatigue [6, 22-27]. Furthermore, LGG patients have specific cognitive problems [5], which presumably may also be related to fatigue.

Moreover, our results show that fatigue is related to other problems. Severely fatigued LGG patients have more problems with regard to self-reported concentration, and they experience reduced motivation and activity. These results are comparable to the extent of problems experienced by patients with chronic fatigue syndrome. However, compared to severely fatigue disease-free cancer patients, the LGG patients in our study report more problems with concentration [6].

In this study no association was found between gender and fatigue severity, but fatigue complaints were more severe in older LGG patients. Also in testicular cancer patients [28] and in patients with hematological malignancies $[29,30]$ the older patients reported more fatigue, whereas in breast cancer patients the younger participants were more fatigued [31].

Furthermore, we found no relation between fatigue severity, tumor characteristics, and former tumor treatment. In one prospective quality of life study it was demonstrated that patients with a high-grade glioma in the right hemisphere were more fatigued than those with a left-sided tumor [32]. However, in most studies, no associations were found between tumor-related variables and fatigue intensity with regard to disease duration [23, 25, 26, 29, 33-35], type of cancer [27, 36], disease stage at diagnosis [23, 25$27,33,37]$, size of the original tumor [25, 26, 37], number of nodes involved [25] and tumor recurrence [33].

Literature data suggest that fatigue arises during the active treatment phase in nearly all cancer patients, but little is known about the etiology of persistent fatigue [711]. Some studies suggest that patients with more aggressive former treatments are more at risk for persistent fatigue [21, 31, 38, 39], but others do not find a strong association between initial cancer treatment and off-treatment fatigue [7-11]. In our study, no differences in fatigue severity were observed for patients who had a biopsy and for patients who underwent a resection. Furthermore, no differences were observed in patients with or without prior radiotherapy. However, fatigue was significantly more pronounced in patients that used AEDs.

This study has its limitations. Small sample size was the reason we had to exclude some variables from the analyses (i.e., oligoastrocytomas, tumors in midline locations). Furthermore, we have no data of current epileptic activity in this study. Therefore, we are not able to distinguish whether seizures or the use of AEDs contributed to the experience of fatigue. It would be very interesting to study a larger group of glioma patients with emphasis on fatigue, AED use, and epilepsy burden. Nonetheless, we conclude that fatigue is a major problem in LGG patients. The current study demonstrates that almost $40 \%$ of long-term survivors with a LGG experience severe fatigue. These findings are important because fatigue has a serious impact on quality of life [40]. Furthermore, a decreased level of quality of life in LGG patients is significantly related to shorter survival [41]. Assessment and treatment of fatigue in LGG patients need to be further investigated, potentially resulting in improvement of quality of life. 
Open Access This article is distributed under the terms of the Creative Commons Attribution Noncommercial License which permits any noncommercial use, distribution, and reproduction in any medium, provided the original author(s) and source are credited.

\section{References}

1. Hickey JV (2003) Brain tumors. In: Hickey JV (ed) The clinical practice of neurological and neurosurgical nursing. Lippincott, Williams \& Wilkins, Philadelphia, pp 483-508

2. Olson JD, Riedel E, DeAngelis LM (2000) Long-term outcome of low-grade oligodendroglioma and mixed glioma. Neurology 54:1442-1448

3. Karim ABMF, Maat B, Hatlevoll R et al (1996) A randomised trial on dose response in radiation therapy of low grade cerebral glioma: EORTC study 22844. Int J Radiat Oncol Biol Phys 36:549-556. doi:10.1016/S0360-3016(96)00352-5

4. Klein M, Engelberts NHJ, van der Ploeg HM et al (2003) Epilepsy in low-grade gliomas: the impact on cognitive function and quality of life. Ann Neurol 54:514-520. doi:10.1002/ana.10712

5. Klein M, Heimans JJ, Aaronson NK et al (2002) Effect of radiotherapy and other treatment-related factors on mid-term to long-term cognitive sequelae in low-grade gliomas: a comparative study. Lancet 360:1361-1368. doi:10.1016/S0140-6736 (02)11398-5

6. Servaes P, van der Werf S, Prins J et al (2001) Fatigue in diseasefree cancer patients compared with fatigue in patients with Chronic Fatigue Syndrome. Support Care Cancer 9:11-17. doi: $10.1007 / \mathrm{s} 005200000165$

7. Servaes P, Verhagen C, Bleijenberg G (2002) Fatigue in cancer patients during and after treatment: prevalence, correlates and interventions. Eur J Cancer 38:27-34. doi:10.1016/S0959-8049 (01)00332-X

8. Prue G, Rankin J, Allen J et al (2006) Cancer-related fatigue: a critical appraisal. Eur J Cancer 42:846-863. doi:10.1016/ j.ejca.2005.11.026

9. Young KE, White CA (2006) The prevalence and moderators of fatigue in people who have been successfully treated for cancer. $\mathrm{J}$ Psychosom Res 60:29-38. doi:10.1016/j.jpsychores.2005.03.011

10. Ng AK, Li S, Recklitis C et al (2005) A comparison between long-term survivors of Hodgkin's disease and their siblings on fatigue level and factors predicting for increased fatigue. Ann Oncol 16:1949-1955. doi:10.1093/annonc/mdi407

11. Hjermstad MJ, Fossa SD, Oldervoll L et al (2005) Fatigue in long-term Hodgkin's disease survivors: a follow-up study. J Clin Oncol 23:6587-6595. doi:10.1200/JCO.2005.09.936

12. Servaes P, Verhagen S, Bleijenberg G (2002) Determinants of chronic fatigue in disease-free breast cancer patients: a crosssectional study. Ann Oncol 13:589-598. doi:10.1093/annonc/ mdf082

13. Bennett B, Goldstein D, Lloyd A et al (2004) Fatigue and psychological distress; exploring the relationship in women treated for breast cancer. Eur J Cancer 40:1689-1695. doi:10.1016/ j.ejca.2004.03.021

14. Sugawara Y, Akechi T, Okuyama T et al (2005) Occurrence of fatigue and associated factors in disease-free breast cancer patients without depression. Support Care Cancer 13:628-636. doi:10.1007/s00520-004-0763-6

15. Gustafsson M, Edvardsson T, Ahlström G (2006) The relationship between function, quality of life and coping in patients with low-grade gliomas. Support Care Cancer 14:1205-1212. doi: 10.1007/s00520-006-0080-3

16. Taphoorn MJB, Klein Schiphorst A, Snoek FJ et al (1994) Cognitive functions and quality of life in patients with low-grade gliomas: the impact of radiotherapy. Ann Neurol 36:48-54. doi: 10.1002/ana.410360111

17. Kiebert GM, Curran D, Aaronson NK et al (1998) Quality of life after radiation therapy of cerebral low-grade gliomas of the adult: results of a randomised Phase III trial on dose response (EORTC trial 22844). Eur J Cancer 34:1902-1909. doi:10.1016/S09598049(98)00268-8

18. Jacobsen PB, Thors CL (2003) Fatigue in the radiation therapy patient: current management and investigations. Semin Radiat Oncol 13:372-380. doi:10.1016/S1053-4296(03)00021-3

19. Vercoulen JH, Alberts M, Bleijenberg G (1999) De Checklist Individual Strength (CIS). Tijdschr Gedragstherapie 32:131-136

20. Vercoulen JH, Swanink CM, Fennis JF et al (1994) Dimensional assessment of chronic fatigue syndrome. J Psychosom Res 38:383-392. doi:10.1016/0022-3999(94)90099-X

21. Servaes P, Gielissen MFM, Verhagen S et al (2006) The course of severe fatigue in disease-free breast cancer patients: a longitudinal study. Psychooncology 16:787-795. doi:10.1002/pon.1120

22. Andrykowski MA, Curran SL, Lightner R (1998) Off-treatment fatigue in breast cancer survivors: a controlled comparison. J Behav Med 21:1-18. doi:10.1023/A:1018700303959

23. Broeckel JA, Jacobsen PB, Horton J et al (1998) Characteristics and correlates of fatigue after adjuvant chemotherapy for breast cancer. J Clin Oncol 16:1689-1696

24. Fobair P, Hoppe RT, Bloom J et al (1986) Psychological problems among survivors of Hodgkin's disease. J Clin Oncol 4: 805-814

25. Hann DM, Jacobsen PB, Martin SC et al (1997) Fatigue in women treated with bone marrow transplantation for breast cancer: a comparison with women with no history of cancer. Support Care Cancer 5:44-52. doi:10.1007/BF01681961

26. Hann DM, Jacobsen P, Martin S et al (1998) Fatigue and quality of life following radiotherapy for breast cancer: a comparative study. J Clin Psychol Med Sett 5:19-33. doi:10.1023/A:102624 9702250

27. Smets EMA, Visser MRM, Willems AFMN et al (1998) Fatigue and radiotherapy: (B) experience in patients 9 months following treatment. Br J Cancer 78:907-912

28. Fossa SD, Dahl AA, Loge JH (2003) Fatigue, anxiety, and depression in long term survivors of testicular cancer. J Clin Oncol 21:1249-1254. doi:10.1200/JCO.2003.08.163

29. Barstch HH, Weis J, Moser MT (2003) Cancer-related fatigue in patients attending oncological rehabilitation programs: prevalence, patterns and predictors. Onkologie 26:51-57

30. So WK, Tai JW (2005) Fatigue and fatigue relieving strategies used by Hong Kong Chinese patients after hemopoietic stem cell transplantation. Nurs Res 54:48-55. doi:10.1097/00006199200501000-00007

31. Woo B, Dibble SL, Piper BF et al (1998) Differences in fatigue by treatment methods in women with breast cancer. Oncol Nurs Forum 25:915-920

32. Brown PD, Ballman KV, Rummans TA et al (2006) Prospective study of quality of life in adults with newly diagnosed high-grade gliomas. J Neurooncol 76:283-291. doi:10.1007/s11060-0057020-9

33. Loge JH, Abrahamsen AF, Ekeberg O et al (1999) Hodgkin's disease survivors more fatigued than the general population. J Clin Oncol 17:253-261

34. Knobel H, Loge JH, Nordoy T et al (2000) High level of fatigue in lymphoma patients treated with high dose therapy. J Pain Symptom Manage 19:446-456. doi:10.1016/S0885-3924(00) 00144-5

35. Okuyama T, Tanaka K, Akechi T et al (2001) Fatigue in ambulatory patients with advanced lung cancer: prevalence, correlated factors, and screening. J Pain Symptom Manage 22:554-564. doi: 10.1016/S0885-3924(01)00305-0 
36. Howell SJ, Radford JA, Smets EM et al (2000) Fatigue, sexual function and mood following treatment for haematological malignancy: the impact of mild Leydig cell disfunction. Br J Cancer 82:789-793. doi:10.1054/bjoc.1999.1000

37. Okuyama T, Akechi T, Kugaya A et al (2000) Factors correlated with fatigue in disease-free breast cancer patients: application of the cancer fatigue scale. Support Cancer Care 8:215-222. doi: $10.1007 / \mathrm{s} 005200050288$

38. Servaes P, Verhagen S, Schreuder HWB et al (2003) Fatigue after treatment for malignant and benign bone and soft tissue tumors. J Pain Symptom Manage 26:1113-1122. doi:10.1016/j.jpainsymman. 2003.03.001
39. Bower JE, Ganz PA, Desmond KA et al (2006) Fatigue in longterm breast carcinoma survivors. A longitudinal investigation. Cancer 106:751-758. doi:10.1002/cncr.21671

40. Portenoy RK (2000) Cancer-related fatigue: an immense problem. Oncologist 5:350-352. doi:10.1634/theoncologist.5-5-350

41. Mainio A, Tuunanen S, Hakko H et al (2006) Decreased quality of life and depression as predictors for shorter survival among patients with low-grade gliomas: a follow-up from 1990 to 2003. Eur Arch Psychiatry Clin Neurosci 256:516-521. doi:10.1007/ s00406-006-0674-2 